\title{
Prevalence of gastro-intestinal parasitic infections in Sheep of Kashmir valley of I ndia
}

\author{
Showkat Ahmad Bhat, Manzoor Ur Rahman Mir, Sawleha Qadir, Idrees Mehraj Allaie, Hilal Musadiq Khan, \\ Ishraq Husain, Bilal Ahmad Sheikh
}

\author{
Faculty of Veterinary Sciences \& Animal Husbandry, \\ Sher-e-Kashmir University of Agricultural Sciences \& Technology Shuhama, \\ Alusteng, Srinagar-190006, Jammu \& Kashmir, India \\ Corresponding author: Manzoor Ur Rahman Mir, email:vbcbiovhemistry@gmail.com \\ Received: 27-03-2012, Accepted: 06-05-2012, Published Online: 17-09-2012 \\ doi: 10.5455/vetworld.2012.667-671
}

\begin{abstract}
Background: Geologically the $\mathrm{J} \& \mathrm{~K}$ state $(2,22,800 \mathrm{sq}$. kms) is both complex and varied. Climatic conditions of the state ranges from sub-tropical (Jammu), temperate (Kashmir) to cold artic (Ladakh) zones and belongs to the great Himalayan mountain range, which exerts significant influence on its agro-climatic conditions. Gastrointestinal parasitism is a major problem in sheep production worldwide, these parasites cause diarrhea, anaemia, reduced weight gain and increased production costs.

Materials and Methods: Five hundred fecal samples of sheep (Ovis aries) were taken from two farms. All fecal samples were examined to determine the prevalence of gastrointestinal parasites. Direct microscopic examination, Centrifugation floatation and Sedimentation techniques were used to examine fecal samples.

Results: Overall prevalence rate was 62.9\%. most commonly encountered parasites were Strongyle spp., Strongyloides spp., Eimeria spp., Nematodirus spp., and Monezia spp. was 24.61, 15.5, 9.8, 9.0 and 3.3\%, respectively. The highest prevalence of G.I parasites was recorded during monsoon season (March - May) followed by summer season (June - August) whereas the lowest prevalence was recorded during winter season. Analysis of the data on the basis of sex revealed a significant difference $(\mathrm{P}<0.05)$ in the overall incidence of gastrointestinal parasites between male $(75.6 \%)$ and female $(44.8 \%)$ sheep. The maximum infection was observed in younger age groups compared to adults $(\mathrm{P}<0.05)$. The prevalence of different species of endoparasites also varied in sheep of different body weight groups $(\mathrm{P}<0.05)$. The highest infection was observed in Kashmir Marino breed than corriedale breed.

Conclusion: The data obtained in this study suggest that the age, sex, body weight and breed are important factors which influence the prevalence of gastrointestinal parasites.

Key wards: climate, economy, faecal sample, Kashmir valley, parasite, prevalence, sheep
\end{abstract}

To cite this article: Bhat SA, Mir MUR, Qadir S, Allaie IM, Khan HM, Husain I, Sheikh BA (2012) Prevalence of gastro-intestinal parasitic infections in Sheep of Kashmir valley of India, Vet World, 5(11): 667-671, doi: 10.5455/vetworld.2012.667-671

\section{I ntroduction}

The state of Jammu \& Kashmir (J\&K) belongs to the great Himalayan mountain range, which exerts significant influence on its agro-climatic conditions. Geologically the J\&K state $(2,22,800$ sq. $\mathrm{kms})$ is both complex and varied. Climatic conditions of the state ranges from sub-tropical (Jammu), temperate (Kashmir) to cold artic (Ladakh) zones [1]. Ruminant animal production, large as well as small, in the lower reaches of Kashmir and the valleys of Jammu region is intensive whereas in mountainous areas, large number are kept under nomadic regime and animals are well adapted to variety of climatic, parasitic and husbandry conditions.
Sheep is unique to the economy of the Kashmir for its wool, mutton, hides and manure. The typical extensive and trans-human (migratory) managemental system of domestic animals in Kashmir, especially sheep, gives it a specific significance to be studied in depth regarding animal adaptability to the extremes of the environment [2]. The state is placed at the highest level with regard to production of fine type of raw wool in the country. About 14 lac people mainly comprising of Gujjar, Bakerwals, Chopans and Marginal farmers are involved in rearing of sheep and goats in the state.

Gastrointestinal parasitism is one of the major health problems severely limiting the productivity of dairy animals in the Himalayan and other hilly regions 
of India [3]. Parasitic infections especially gastrointestinal nematode and trematode pose a serious health threat and limit the productivity of livestock due to the associated morbidity, mortality, cost of treatment and control measures [4,5]. The prevalence of helminths of small ruminants results in low productivity due to stunted growth, poor weight gain and poor feed utilization [6]. Helminthiasis adversely affects ruminants, causing hematological, biochemical disturbances, anorexia, weight loss, poor reproductive performance, and even death of lambs [7,8]. In Kashmir parasitism is one of the major threats for livestock, especially causing obstacles to the development of a profitable sheep industry [9]. Gastrointestinal parasites decrease the resistance to diseases and even cause severe mortality thus leading to heavy loss [10]. These loses were estimated at 48.4 million Ethiopian Birr per year of which $46.5,48.8$ and $4.7 \%$ were due to mortality, productivity (weight loss and reproductive problems) and live condemnation, respectively. A decrease in profitability up to $15 \%$ and weight loss up to $50 \%$ due to gastrointestinal parasites have been reported [11].Although, work has been done on endoparasites of sheep in Kashmir [12-15]. Keeping in view the importance of gastrointestinal endoparasites in animals, the present study was executed to investigate the prevalence of gastrointestinal parasites in sheep reared under traditional husbandry system in Kashmir.

\section{Materials and Methods}

A survey of the prevalence of gastro-intestinal tract (GIT) parasites in 500 sheep was conducted in different area of Kashmir during the period of February 2011 to January 2012. A total of 500 sheep including 250 males and 250 females were taken from two farms, Sheep Research Station (SRS) Shuhama Srinagar of Faculty of Veterinary Sciences \& Animal Husbandry (F.V. Sc \& A.H), Sher-e-Kashmir University of Agricultural Sciences \& Technology of Kashmir SKUAST-K India \& SRS Dachigam sheep Husbandry Department Srinagar Kashmir India were examined for the prevalence of gastrointestinal parasites. Depending upon the age, these animals were divided into six groups, viz. 12-24 ( $\mathrm{n}=90), 25-37(\mathrm{n}=105), 38-50(\mathrm{n}=120)$, 51-63 $(\mathrm{n}=50), 64-76(\mathrm{n}=85)$ and 77-89 months $(\mathrm{n}=50)$ with four body weight groups i.e. 14-24 $(n=105), 25$ $35(\mathrm{n}=220), 36-46 \quad(\mathrm{n}=130)$ and $>46 \mathrm{~kg} \quad(\mathrm{n}=45)$ belonged to two breeds i.e. Corriedale $(n=270)$ and Kashmir Marino $(n=230)$. The relationship between different groups of the host and GIT parasites were studied. From each animal under study, 5 to 10 grams of fecal material was collected directly from the rectum. Samples were brought to the Parasitology \& Biochemistry Laboratories, Division of Veterinary Parasitology \& Division of Biochemistry respectively, of F.V. Sc \& A.H. (SKUAST-K), for identification of eggs / larvae of different gastrointestinal parasites. Direct microscopic examination, centrifugation floatation and sedimentation techniques were used to examine fecal samples [16].

Statistical analysis: In order to see the magnitude of variation in the prevalence of endoparsites among sheep of various groups, the data were analyzed statistically using Chi square test.

\section{Results}

Strongyle spp.was significantly $(\chi 2=62.12, \mathrm{P}=0.00)$ most prevalent than Strongyloides spp., Eimeria spp., Nematodirus spp. and Monezia spp. (Table1). The maximum incidence of Strongyle group was recorded in both gender, followed by Strongyloides spp., Eimeria spp., Nematodirus spp. and Monezia spp. respectively (Table 2). But the parasites spp. were more prevalent in male hosts as compared to female hosts $(\chi 2=7.95$, df $=3, P=0.047)$.

Table-1. Overall prevalence of Gastrointestinal ( G.I) parasites of sheep

\begin{tabular}{lcc}
\hline G.I Parasites & No. of sheep & Prevalence (\%) \\
\hline Strongyle spp. & 123 & 24.61 \\
Strongyloides spp. & 77 & 15.5 \\
Eimeria spp. & 49 & 9.8 \\
Nematodirus spp. & 45 & 9.0 \\
Monezia spp. & 17 & 3.3 \\
Total & 311 & 62.9 \\
\hline
\end{tabular}

Percentage has been calculated from total number of animals examined $(n=500)$. The prevalence of various GIT parasites differed significantly $\left(\chi_{2}=62.12\right.$, df $\left.3, P=0.00\right)$.

The results of relationships between age and endoparasites of sheep are shown in (Table 3). The highest prevalence rate of GIT parasite occurred in younger age groups while the lowest prevalence was recorded in older age groups. The results represents that younger animal had significantly higher prevalence than older animals $(\chi 2=381.0$, df $=25$, $\mathrm{P}=0.000)$ The relationship between body weight and endoparasites of sheep was recorded (Table 4). The data indicated the prevalence of Strongyle spp., Strongyloides spp., Eimeria spp., Nematodirus spp. and Monezia spp. were maximum in lower body weight groups, as compared to the animals with normal body weight. Hence prevalence of G.I parasites was significantly higher in lower body weight animals $(\chi 2=22.45, \mathrm{df}=12, \mathrm{P}=0.033)$. The results of relationship between different breeds and 
Prevalence of gastro-intestinal parasitic infections in Sheep of Kashmir valley of India

Table-2. Relationship between sex and gastrointestinal parasite spp.

\begin{tabular}{|c|c|c|c|c|}
\hline Name of Parasites & \multicolumn{2}{|c|}{ Male hosts $(n=250)$} & \multicolumn{2}{|c|}{ Female hosts $(n=250)$} \\
\hline Strongyle spp. & 66 & 26.38 & 56 & 22.50 \\
\hline Eimeria spp. & 38 & 15.27 & 14 & 5.50 \\
\hline Nematodirus spp. & 35 & 13.88 & 11 & 4.42 \\
\hline Monezia spp. & 5 & 2.0 & 3 & 1.3 \\
\hline Df & \multirow{2}{*}{\multicolumn{2}{|c|}{$\begin{array}{c}7.95 \\
3 \\
0.047\end{array}$}} & \multirow{2}{*}{\multicolumn{2}{|c|}{$\begin{array}{c}64.42 \\
3 \\
0.000\end{array}$}} \\
\hline $\mathrm{P}$ Value & & & & \\
\hline
\end{tabular}

Parasite spp. were more Prevalent in male hosts as compared to female hosts $(\chi 2=7.95, d f=3, P=0.047$ )

Table-3. Prevalence of various gastrointestinal parasite spp. of sheep $(n=500)$ in relation to age

\begin{tabular}{lllllll}
\hline Parasites & & \multicolumn{7}{c}{ Age groups of sheep (Months) } \\
& $\mathbf{1 2 - 2 4}(\mathbf{n = 9 0 )}$ & $\mathbf{2 5 - 3 7}(\mathbf{n = 1 0 5 )}$ & $\mathbf{3 8 - 5 0}(\mathbf{n = 1 2 0 )}$ & $\mathbf{5 1 - 6 3 ( n = 5 0 )}$ & $\mathbf{6 4 - 7 6}(\mathbf{n = 8 5})$ & $\mathbf{7 7 - 8 9}(\mathbf{n = 5 0 )}$ \\
\hline Strongyle spp. & $24(27.12)$ & $14(13.60)$ & $28(23.68)$ & $11(21.27)$ & $20(23.61)$ & $4(8.33)$ \\
Strongyloides spp. & $15(17.08)$ & $5(4.52)$ & $16(13.15)$ & $5(9.57)$ & $13(15.27)$ & $4(8.33)$ \\
Eimeria spp. & $12(13.18)$ & $3(3.10)$ & $6(5.26)$ & $3(6.38)$ & $3(4.17)$ & $0(0)$ \\
Nematodirus spp. & $10(11.60)$ & $2(1.46)$ & $5(4.38)$ & $4(7.44)$ & $0(0)$ & $1(2.08)$ \\
Monezia spp. & $1(1.5)$ & $2(1.6)$ & $0(0)$ & $0(0)$ & $0(0)$ & $0(0)$ \\
\hline
\end{tabular}

Figures in parenthesis indicate percentage. The prevalence of various GIT parasites in relation to age differed significantly $(x 2=381.00, d f=25, P=0.00)$.

Table-4. Relationship between body weights with some gastrointestinal parasites of sheep $(n=500)$ in Kashmir valley

\begin{tabular}{|c|c|c|c|c|}
\hline \multirow[t]{2}{*}{ Parasites } & \multicolumn{4}{|c|}{ Body weight groups of sheep $(\mathbf{k g})$} \\
\hline & $14-24(n=105)$ & $25-35(n=220)$ & $36-46(n=130)$ & $>46 \mathrm{~kg}(n=45)$ \\
\hline Strongyle spp. & 27 (26.24) & $41(18.60)$ & $29(22.38)$ & $7(15.15)$ \\
\hline Strongyloides spp. & 18 (17.02) & $21(9.76)$ & $15(11.19)$ & $5(12.12)$ \\
\hline Eimeria spp. & $11(10.63)$ & $9(4.18)$ & $8(5.97)$ & $3(6.06)$ \\
\hline Nematodirus spp. & $10(9.21)$ & $10(4.65)$ & $6(4.47)$ & $1(2)$ \\
\hline Monezia spp. & $1(1)$ & $2(1)$ & $0(0)$ & $0(0)$ \\
\hline
\end{tabular}

Figures in parenthesis indicate percentage. The prevalence of various GIT parasites in relation to body weight differed significantly $\left(\chi_{2}=22.45, \mathrm{df}=12, \mathrm{P}=0.033\right)$.

gastrointestinal parasite revealed the highest infection in Kashmir Marino 73/250 (29.22\%) as compared to Corriedale 66/250 (26.51\%)but the difference was non significant $(\chi 2=0.259, \mathrm{df}=1, \mathrm{P}=0.611)$.

\section{Discussion}

A total of 500 sheep were examined, out of which 311 were found to contain various GIT parasites. The overall prevalence rate was $62.9 \%$. Prevalence of, Strongyle spp. Strongyloides, Eimeria, Nematodirus, and Monezia spp. was 24.61, 15.5, 9.8, 9.0 and 3.3\%, respectively. The highest prevalence of G.I parasites was recorded during monsoon season (March - May) followed by summer season (June - August) whereas the lowest prevalence was recorded during winter season. The increase in their prevalence during summer may be due to increase in humidity and availability of favorable temperature. The various species of endo- parasites recovered during present investigation have been reported by various researchers in different parts of the world $[4,6,17,18,19]$. The prevalence recorded in the present study was similar to the studies reported by Nwosu, et al. [4]. The rate of helminths infection in sheep varies in different parts of the world. A variety of factors like grazing habits, level of education and economic capacity of the farmers, standard of management and anthelmintic used can influence the prevalence of helminths. Prevailing agro-climatic conditions like overstocking of animals, grazing of young and adult animals together with poorly drained land provide an ideal condition for the transmission of endoparasites to build up clinical infestation of the host [18].

All the livestock in the area under investigation largely depend on grazing in deteriorated rang-lands. It was also observed that farms in these areas lack fences and cattle, sheep and goats use the same pasture 
for grazing. Sex wise observations revealed that the prevalence of gastrointestinal parasites was more in males $(\mathrm{P}<0.05)$ than females. The results of the present study are supported by Kanyari et al. who found females were more resistant to infection than males after puberty [20] also Raza MA. et al. reported the same that ram were more susceptible to gastrointestinal parasites parasite as compared to ewe [7]. Lashari et al [5] reviewed the effect of host sex on resistance levels [20]. These differences were observed around or after puberty, and no difference was observed prior to puberty. He also reported that these differences may be due to a stimulatory effect of estrogens on immune responses and that androgens may actually have an opposite effect [21]. The influence of sex on the susceptibility of animals to infections could also be attributed to genetic predisposition and differential susceptibility owing to hormonal control. Testosterone is known for its immunosuppressive activity [22], and this has often been invoked as the major reason for the higher susceptibility of males to vide variety of infectious diseases [23].

The results of the present study are in agreement with $[17,19,24]$ who reported prevalence of gastrointestinal parasite infection of sheep higher $(\mathrm{P}<0.05)$ in rams than in ewes. The results of present investigation have revealed that age of the host seems to have influence on the prevalence of infection. Age-wise results revealed the highest prevalence in younger age groups of sheep and with increase in age, the infection level decreased $(\mathrm{P}<0.05)$. The low level of gastrointestinal parasites reported in adult hosts may be due to the development significant immunity. Age is an important factor in the onset of infection in host body. [17,25].Tasawar, et al [19] reported that the age of animal has a significant influence on the level of risk of gastrointestinal infections in sheep with higher prevalence in young goats than adults [19].reported that the younger animals were more susceptible to nematode parasites compared to older age animals. The present results are also in accordance with the results reported by Tariq et al [26]. Relationship between body weight of sheep and parasites showed that the endoparasites had highest prevalence in lower body weight group and lowest in higher body weight group of sheep. The results show that as the weight of animal increases the parasitic infection decreases. The results were substantiated by Kanyari et al. [20] and Tasawar et al. [19]. They reported that sheep and goats having lower body weight were heavily infected with endoparasites than those having higher body weight. This could be due to the acquired immunity. In the present study non significant $(\mathrm{P}>0.05)$ relationship was found in sheep breed and gastrointestinal parasites. But the result showed Kashmir Marino had slightly higher prevalence than corriedale breed. Similar results were found by Wildeus, et al. [27] and $\mathrm{Li}$, et al [28] reported the highest gastrointestinal parasitic infection in Suffolk than gulf coast native breeds of sheep in Gulf Coast region of United State.

\section{Conclusion}

In conclusion, the present study indicated that sex, age, body weight and breed are important factors which influence the prevalence of gastrointestinal parasitic infection in sheep in Kashmir Valley. The infections may be very important economically leading to retarded growth; reduced productivity and animals are more susceptible to other infections. However, the combination of strategic use of anthelmintics with traditional veterinary medicine and good management could improve the control of gastrointestinal parasitic infection in sheep.

\section{Author's contribution}

All the authors have contributed equally. All authors read and approved the final manuscript.

\section{Acknowledgements}

The study was supported by J\&K State Council for Science and Technology, Department of Science and Technology Srinagar (Government of Jammu \& Kashmir) vide Research grant to the corresponding author.

\section{Competing interests}

Authors declare that they have no competing interests.

\section{References}

1. Jammu \& Kashmir (2001) Information Department Publication. Govt. of J\&K.

2. Gupta, J.L., (1994) Sheep development in temperate region. CBS Publishers \& Distributors.

3. Jithendran, K.P., Bhat, T.K., 1999. Epidemiology of parasites in dairy animals in the north-west humid Himalayan region of India with particular reference to gastro-intestinal nematodes. Tropical Animal Health and Production. 31, 205-214.

4. Nwosu, C.O., Madu, P.P., Richards, W.S., (2007) Prevalence and seasonal changes in the population of gastrointestinal nematodes of small ruminants in the semi-arid zone of North-Eastern Nigeria. Vet Parasitol. 144, 118-124.

5. Lashari MH, Z Tasawar. (2011) Prevalence of some gastrointestinal parasites in sheep in southern Punjab, Pakistan. Pak Vet J. 31, 295-298. 
6. Pedreira, J., Silva, A.P., Andrade, R.S., Suarez, J.L., Arias, M., Lomba, C., et al. (2006) Prevalence of gastrointestinal parasites in sheep and parasite control practices in North-West Spain. Prev Vet Med. 75, 5662.

7. Khajuria, J.K., and Kapoor, P.R., (2003) Prevalence of parasites in sheep and goats at Kathua-Jammu. Journal of Veterinary Parasitology. 17, 121-126.

8. Hussain, H.U., and Usmani, R.H., (2006) Livestock of Pakistan. 1st Ed., Livestock Foundation, Islamabad.

9. Mir, R.A., Chishti, M.Z., Zargar, M.A., Tak, H., Dar, F.A., (2008) Seasonal prevalence of trematode parasites of sheep (Ovis aries L.) in Kashmir Valley, India Nig. Jour. Parasitology. 29,80-83.

10. Ngategize, P.K., Bekele, T., and Tilahun,G., (1993) Financial losses caused by ovine fasciolosis in the Ethiopian highlands. Trop Anim Health and Prod. 25, 155-161.

11. Hussain, Q., (1985) Studies on the incidence of gastrointestinal parasites and efficacy of Banmnth-II against nematodes in buffalo calves. M.Sc. Thesis, Dept Parasitol, Univ Agric, Faisalabad, Pakistan.

12. Makhdoomi, D.M., Nasreen, S., Bandey, S.D., Moulvi, B., (1995) Incidence of different ovine gastrointestinal parasites in Kasgmir. Indian Veterinary Journal.75, 363-367.

13. J. Uriarte, M.M. Llorente, J. Valderrábano. (2003). A Seasonal changes of gastrointestinal nematode burden in sheep under an intensive grazing system, Veterinary Parasitology. 118, 79-92.

14. Bhat, S.A., Manzoor, R.M., Qadri, S., Allaie, I., Khan, H.M, et al. (2011) Comparative Resistance of Sheep Breeds to Strongyle spp.in Pasture Infection in Jammu and Kashmir. I J Vety. Sci Technol. 10.4172,21577579.1000110.

15. Shahnawaz M., Shahardar R.A., Wani Z.A., (2011) Seasonal prevalence of platyhelminthosis of sheep in gandarbal area of Kashmir Vally. Veterinary Parasitology. 25, 59-62.

16. Cable, R.M., (1985) In An Illustrated Laboratory Manual of Parasitology; 5th Ed, Surjeet Publications, Delhi, India.

17. Raza, M.A., Iqbal, Z., Jabbar, A., and Yaseen, M., (2007) Point prevalence of gastrointestinal helminthiasis in ruminants in southern Punjab, Pakistan. $J$ Helminthol. 81, 323-328.

18. Gadahi, J.A., Arshad, M.J., Ali, Q., Javaid, S.B., Shah, S.I., (2009) Prevalence of gastrointestinal parasites ofsheep and goats in and around Rawalpindi, Islamabad. Vet World. 2, 51-53.

19. Tasawar, Z., Ahmad, S., Lashari, M.H., Hayat, C.S., (2010) Prevalence of Strongyle spp.in sheep at Research Centre for Conservation of Sahiwal Cattle (RCCSC) Jehangirabad, District Khanewal, Punjab, Pakistan. PakJZool. 42, 735-739.

20. Kanyari, P.W., Kagira, J.M., Mhoma, R.J., (2009) Prevalence and intensity of endoparasites in small ruminants kept by farmers in Kisumu Municipality, Kenya. Livestock Res Rural Develop. 21, 111-116.

21. Bilbo, S.D., Nelson, R.J., (2001) Sex steroid hormones enhance immune function in male and female Hamsters. Am J Physiol. 280, 207-213.

22. Barger, I.A., (1993) Influence of sex and reproductive status on susceptibility of ruminants to nematode parasitism. Int J Parasitol. 23, 463-469.

23. Roberts, C.W., Walker, W., Alexander, J., (2001) Sex associated hormones and immunity to protozoan parasites. Clin Microbiol Rev. 4, 476-488

24. Gualy, M., Schackert, M., Hoffman, B., Erkardt, G., (2006) Influence of sex on the resistance of sheep lambs to an experimental Haemonchus contotus infection. Dtsch Tierarztl Wochenschr. 113, 178-181.

25. Magona, J.W., Musisi, G., (2002) Influence of age, grazing system, season and agroclimatic zone on the prevalence and intensity of gastrointestinal strongylosis in Ugandan goats. Small Rum Res. 44, 187-192.

26. Tariq, K.A., Chisti, M.Z., Ahmad, F., Shawl, A.S., (2008) Epidemiology of gastrointestinal nematodes of sheep managed under traditional husbandry system in Kashmir Valley. Vet Parasitol. 158, 138-143.

27. Wildeus, S., Zajac, A.M., (2005) Gastrointestinal parasitism in hair sheep and meat goat breeds grazing naturally infected pasture. Sheep Goat Res J. 20, 4246.

28. Li, Y., Miller, J.E., Franke, D.E., (2001) Epidemiology, observation and hetrosis analysis of gastrointestinal nematode parasitism in Suffolk, Gulf Coat Native and cross-breed lambs. Vet Parasitol. 98, 273-283. 